\title{
«Le Courrier balzacien» 31
}

\section{Marco Stupazzoni}

\section{OpenEdition}

\section{Journals}

\section{Edizione digitale}

URL: http://journals.openedition.org/studifrancesi/5383

DOI: 10.4000/studifrancesi.5383

ISSN: 2421-5856

\section{Editore}

Rosenberg \& Sellier

\section{Edizione cartacea}

Data di pubblicazione: 1 dicembre 2016

Paginazione: $543-544$

ISSN: 0039-2944

\section{Notizia bibliografica digitale}

Marco Stupazzoni, « «Le Courrier balzacien» 31 », Studi Francesi [Online], 180 (LX | III) | 2016, online dal 01 janvier 2017, consultato il 18 septembre 2020. URL : http://journals.openedition.org/studifrancesi/ 5383 ; DOI : https://doi.org/10.4000/studifrancesi.5383

Questo documento è stato generato automaticamente il 18 settembre 2020 .

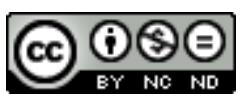

Studi Francesi è distribuita con Licenza Creative Commons Attribuzione - Non commerciale - Non opere derivate 4.0 Internazionale. 


\title{
«Le Courrier balzacien» 31
}

\author{
Marco Stupazzoni
}

\section{NOTIZIA}

«Le Courrier balzacien», nouvelle série, n. 31, janvier 2015, 67 pp.

1 Xavier BOURDENET (Stendhal: l'amour dans tous ses états, pp.5-14) illustra i concetti fondamentali che informano il discorso stendhaliano sull'amore riferendosi, in modo particolare, a tre idee essenziali: il carattere complesso e plurale dell'amore; la nozione di 'cristallisation', vera e propria metafora della «puissance fabuleuse qui est à l'origine de l'amour» (p. 8); il legame intimo tra amore e bellezza «qui fait de l'amour un remodelage du réel» (p. 12) attraverso le forme dell'esperienza estetica. In De l'amour (1822), è presente una «esthétisation de l'érotique» ed una «érotisation de l'esthétique», afferma l'A.: "c'est l'une des leçons universelles de De l'amour, qui s'affirme par là pleinement romantique» (p. 14).

2 Lucette BESSON (Stendhal, "un des hommes les plus remarquables de ce temps», pp. 15-30) studia, con rigore, l'influenza di De l'Amour sull'opera di Balzac a partire da alcuni romanzi giovanili e, soprattutto, dalla Physiologie du mariage. Stendhal, osserva l'A., «a érigé en théorie une longue tradition de situations sentimentales qui, jusque là, avaient échappé à toute nomenclature, et Balzac, ayant reconnu la pertinence de ce travail à la fois d'analyse et de synthèse, a suivi son propre chemin sous la caution, tacite ou avouée, de son devancier» (p. 30).

3 Jacques HOUBERT (Une bourde de Balzac, pp. 31-33) evidenzia, a proposito del saggio sulla Chartreuse de Parme («Revue parisienne», 25 septembre 1840), le eccessive libertà prese da Balzac nel trascrivere lo svolgimento di alcuni episodi del romanzo stendhaliano.

4 François BRONNER (Quand Balzac et Stendhal parlaient d'Habeneck, pp. 34-40) offre un accurato profilo di François Antoine Habeneck, direttore d'orchestra e personalità di spicco del mondo musicale parigino della prima metà del xIX secolo. Marginalmente presente nella vita e negli scritti di Stendhal, la figura di questo musicista ha 
attraversato in maniera significativa la vita di Balzac. In particolare, scrive l'A., «c'est à propos de Beethoven (et plus généralement avec la Société des concerts du Conservatoire) que les rapports entre les deux personnalités furent les plus importants» (p. 36). Balzac, che cita Habeneck in César Birotteau e in Splendeurs et misères des courtisanes, ha avuto modo di apprezzare più volte le sue qualità di direttore d'orchestra all'Opéra: «il en parle alors comme d'une personnalité bien connue dont le nom ne peut être ignoré de ses lecteurs» (p. 40).

5 Max ANDRÉOLI (La guerre vue par Balzac dans "La Comédie humaine“, pp. 41-51) illustra, in questo interessante studio, il carattere e il valore storico-letterario, morale e filosofico della rappresentazione della guerra nella Comédie humaine. «La guerre est la débauche du sang», scrive Balzac ne La Peau de chagrin: da questo punto di vista, le intense pagine dedicate alla descrizione del terribile disastro dell'armata napoleonica sulla Beresina in Adieu costituiscono una testimonianza esemplare del ruolo incarnato dalla fatalità nello svolgersi delle vicende umane. Balzac, «sensible à ce que la guerre recèle de beautés, d'infamies et d'atrocités, cherche à en faire ressortir le caractère esthétique, aux sens originel et artistique de ce mot» (p. 43).

6 Lo stesso Max ANDRÉOLI (À la mémoire de Roland Chollet, pp. 52-54) ricorda l'alto profilo critico di Roland Chollet non solo come autorevole specialista di Balzac, ma anche come «homme de large culture classique et de vastes horizons» (p. 53), appassionato cultore delle lettere italiane con una predilezione particolare per Giacomo Leopardi.

7 Segnaliamo, infine, due pregevoli interventi di Anne-Marie BARON con i quali si chiudono i contributi critici presenti in questo fascicolo: «Pour que tu ne te perdes pas dans le quartier». Modiano, émule de Proust ou de Balzac? (pp. 55-57) e Picasso et Balzac (pp. 58-60). 